\title{
An indolylquinoline derivative activates DNA damage response and apoptosis in human hepatocellular carcinoma cells
}

\author{
CHUN-YEN LIU $^{1 *}$, CHANG-HUNG HSIEH $^{1^{*}}$, SEUNG-HUN KIM ${ }^{1}$, JING-PING WANG $^{1}$, \\ YU-LIN NI ${ }^{1}$, CHUN-LI SU ${ }^{2}$, CHING-FA YAO ${ }^{3}$ and KANG FANG ${ }^{1}$ \\ Departments of ${ }^{1}$ Life Science, ${ }^{2}$ Human Development and Family Studies, and ${ }^{3}$ Chemistry, \\ National Taiwan Normal University, Taipei 116, Taiwan, R.O.C.
}

Received July 27, 2016; Accepted September 14, 2016

DOI: $10.3892 /$ ijo.2016.3717

\begin{abstract}
Human liver cancer is one of the most frequently diagnosed cancers worldwide. The development of resistance to therapy limits the application against the disease. To improve treatment, new effective anticancer agents are constantly pursued. Previously, we reported that an indolylquinoline, 3-((7-ethyl-1H-indol-3-yl)-methyl)-2-methylquinoline (EMMQ), is effective in suppressing the growth of human lung cancer by impairing mitochondria functions. The present study revealed that EMMQ inhibited cell growth and induced apoptosis in liver cancer cells, but not in normal cells. This study demonstrated that EMMQ induced DNA damage by activating p53 and $\gamma-\mathrm{H} 2 \mathrm{AX}$ and cell arrest by suppressing cyclin D1 and CDK2. Damaged DNA injured mitochondrial functions by lowering the membrane potential and producing reactive oxygen species. The subsequent mitochondrial cytochrome $c$ release attenuated pro-survival signals and increased apoptotic characteristics. Introduction of p53 shRNA abrogated drug effects by reducing DNA damage while maintaining mitochondria integrity. In brief, the study demonstrates that the effectiveness of EMMQ accentuated apoptosis of hepatocarcinoma cells by activating p53. Based on these collective findings, the study offered a new perspective of EMMQ that was shown to be a promising candidate to treat liver cancer.
\end{abstract}

\section{Introduction}

Liver cancer is one the most frequently encountered cancers and the second most frequent cause of cancer-related death worldwide $(1,2)$. The most common type of liver cancer is hepatocellular carcinoma (HCC) that accounts for $85-90 \%$ of

Correspondence to: Professor Kang Fang, Department of Life Science, National Taiwan Normal University, 88 Ting-Chow Road, Sec 4, Taipei 116, Taiwan, R.O.C.

E-mail: kangfang@ntnu.edu.tw

*Contributed equally

Key words: indolylquinoline, human liver cancer cells, apoptosis the liver cancer (3). Currently, platinum-analogue agents are the widely used chemotherapeutic drugs for treating HCC (4). The platinum-based analogs, including cisplatin and carboplatin, formed DNA crosslinks that significantly attenuated the growth of tumors. However, their use is restricted by the development of resistance (5-7). The acquired drug resistance to platinum analogue regimen is responsible for the diminished efficacy in HCC patient treatments. Therefore, more new effective therapy strategies are constantly needed.

Previously, we reported that a small molecular weight indolylquinoline derivative with connection of indole and quinoline functional groups, 3-((7-ethyl-1H-indol-3-yl)-methyl)2-methylquinoline (EMMQ), that reduced the growth of human lung cancer cells through apoptotic death (8). The newly synthetic EMMQ available in the authors' group has not been assessed for preventive, protective and usefulness in different diseases. To demonstrate the effectiveness of the compound, more systematic investigations in different types of cancer are undertaken. This study found that EMMQ is effective in suppressing the growth in HCC cells and the developed apoptosis accounts for the drug sensitivity. The study showed that the reduced cell viabilities in HepG2 cells began with DNA damage, followed by the decrease of mitochondrial membrane potential $(\Delta \Psi \mathrm{m})$. Generation of reactive oxygen species (ROS) and release of cytochrome $c$ contributed to final apoptotic cell death. The development of apoptosis in HepG2 cells began with DNA damage and activation of tumor suppressor p53 that contributed to cleavage of poly(ADP-ribose) polymerase (PARP) and procaspase-3 in addition to attenuation of pro-survival signals. Furthermore, transfection of small hairpin RNA (shRNA) of p53 suppressed DNA damage and restored mitochondrial functions that recovered cell viabilities and reduced drug sensitivity. In view of the constant need to acquire more drugs for chemotherapy, the elucidated mechanism provides EMMQ a new perspective to treat human liver cancer cells.

\section{Materials and methods}

Cell culture and chemicals. Human hepatocellular carcinoma cell lines, HepG2 (wild-type p53) and Hep3B (p53-null) were acquired from the American Type Culture Collection (ATCC; Manassas, VA, USA). Huh7 (mutant p53) cells were from the Japanese Collection of Research Bioresources (http:// 
p53.free.fr/Database/Cancer_cell_lines/HCC.html). Normal human liver cell line L02 was purchased from the Chinese Academy of Science Committee Type Culture Collection Cell Bank (Wuhan, China). The cells were cultured in Dulbecco's modified Eagle's medium (DMEM) supplemented with L-glutamine, sodium pyruvate and $10 \%$ fetal bovine serum (FBS) at $37^{\circ} \mathrm{C}$ in a humidified atmosphere with $5 \% \mathrm{CO}_{2}$. The synthetic indolylquinoline, EMMQ, was prepared according to the procedures previously described (8).

Cell growth assay. Cell growth inhibition or cell numbers were determined by measuring dye absorbance of 3-(4,5-dimethylthiazol-2yl)-2,5-diphenyltetrazolium bromide (MTT) or counting trypan blue exclusion cells. A density of $3 \times 10^{3}$ cells/well were seeded in 96-well microtiter plates for MTT assay. Cells were allowed to attach overnight and then treated with various concentrations of EMMQ in $2 \%$ serum-supplemented media at $37^{\circ} \mathrm{C}$ for $48 \mathrm{~h}$. After removing the supernatant, formazan crystals were dissolved in $100 \mu 1$ dimethyl sulfoxide (DMSO) and the absorbance measured at $570 \mathrm{~nm}$. The concentration inhibiting $50 \%$ growth was determined as $\mathrm{IC}_{50}$.

Colony forming assay. Cells were seeded at 500 cells/well in a 12 -well plates for $16 \mathrm{~h}$ to allow for attachment. The cells were treated with various concentrations of EMMQ or vehicle control for $48 \mathrm{~h}$ at $37^{\circ} \mathrm{C}$ and $5 \% \mathrm{CO}_{2}$ in a humidified environment. After 10 days, the plates were washed twice in phosphate-buffered saline (PBS), fixed with paraformaldehyde, stained with $0.05 \%$ crystal violet, washed with PBS and air-dried. The sizes and numbers of stained colonies composing of $>50$ cells were counted under inverted phase contrast microscope. Colony formation containing colony numbers with $>50$ cells was calculated and converted as percentage relative to DMSO control.

Comet assay. The cells as cultured in 12-well plates at a density of $1 \times 10^{5}$ cells/well were incubated with various concentrations of EMMQ at different time-points. Afterwards, cells were harvested and mixed with low melting point agarose at $37^{\circ} \mathrm{C}$. This mixture was placed on the top of the slide with $0.5 \%$ agarose, and then covered with a coverslip until solidified. Subsequently, the coverslip was removed gently and more agarose added and covered again. The slide was placed until the mixture became solid, and put in chilled alkaline lysis buffer for electrophoresis. The slide was then gently washed with neutralized buffer and stained with propidium iodide (PI; Aldrich-Sigma, St. Louis, MO, USA). The tails were observed under a fluorescence microscope and quantified using CometScore ${ }^{\mathrm{TM}}$ software and scored for tail moment that equals the measured tail length multiplied with fraction of total DNA in the tail.

Flow cytometric analysis of the cell cycle. Cells were pretreated with nocodazole ( $200 \mathrm{ng} / \mathrm{ml}$; Aldrich-Sigma) for $24 \mathrm{~h}$ to arrest cells at the $\mathrm{G}_{2} / \mathrm{M}$-phase and changed to fresh medium for $3 \mathrm{~h}$ to synchronize cells in $\mathrm{G}_{1}$-phase before being treated with EMMQ for $48 \mathrm{~h}$ and collected by trypsin-EDTA and 3,000 rpm centrifugation for $5 \mathrm{~min}$. The cell pellet was suspended with $70 \%$ ethanol at $-20^{\circ} \mathrm{C}$ overnight, washed with PBS, then incubated with $10 \mu \mathrm{g} / \mathrm{ml}$ RNase A and PI, respectively, for $20 \mathrm{~min}$ in darkness at $37^{\circ} \mathrm{C}$. Flow cytometry was used to detect cell cycle distribution. Data were plotted and analyzed by FlowJo software.
Measurement of intracellular reactive oxygen species. The intracellular reactive oxygen species (ROS) was detected by staining cells with $2^{\prime}, 7^{\prime}$-dichlorofluorescein diacetate (DCF-DA). The hepatocellular carcinoma cells were cultured in 12-well plates at a density of $1 \times 10^{5}$ cells/well and incubated with various concentrations of EMMQ for 6 and $24 \mathrm{~h}$, respectively. Cells were incubated with $10 \mu \mathrm{M}$ DCF-DA for $30 \mathrm{~min}$ at $37^{\circ} \mathrm{C}$. Cells were washed twice with PBS (pH 7.4), and the fluorescence intensity was recorded by flow cytometer FACSCalibur $^{\mathrm{TM}}$ (BD Bioscience, San Jose, CA, USA). Data were analyzed using FlowJo software (FlowJo, LLC Ashland, OR, USA).

Double staining with Annexin V-FITC and PI. Cells were seeded at $1 \times 10^{5}$ cells/well in 12 -well plates and treated with various concentrations of EMMQ and incubated at $37^{\circ} \mathrm{C}$ for $48 \mathrm{~h}$. The cells were trypsinized and stained with $1 \mu \mathrm{l}$ Annexin V/FITC $(20 \mu \mathrm{g} / \mathrm{ml}$; BD Biosciences) and $1 \mu \mathrm{l}$ of PI $(50 \mu \mathrm{g} / \mathrm{ml})$ at $37^{\circ} \mathrm{C}$ for $30 \mathrm{~min}$ in the dark. The early and late phase of apoptosis was analyzed by Annexin V-FITC/PI apoptosis detection kit (BD Biosciences). The flow cytometer FACSCalibur (BD Biosciences) was used for analysis. Data were analyzed using the FlowJo software.

Mitochondrial membrane potential $(\Delta \Psi m)$. Mitochondrial membrane potential was determined using MitoPT ${ }^{\mathrm{TM}}$ JC-1 assay kit (ImmunoChemistry Technologies, Bloomington, IN, USA). Briefly, the cells were cultured in medium containing various concentration of EMMQ and incubated at $37^{\circ} \mathrm{C}$ for different time-points. The collected cells were washed with $1 \mathrm{X}$ assay buffer. After centrifugation at $1,000 \mathrm{rpm}$ for $5 \mathrm{~min}$, cell pellets were stained with $250 \mu \mathrm{l}$ mixture containing $5 \mu \mathrm{l}$ of 5,5',6,6'-tetrachloro-1,1',3,3'-tetraethyl benzimidazolocarbocyanine iodide (JC-1) with $995 \mu \mathrm{l} 1 \mathrm{X}$ assay buffer for $25 \mathrm{~min}$ at $37^{\circ} \mathrm{C}$. The residual JC-1 were removed by centrifugation at $1,000 \mathrm{rpm}$ for $5 \mathrm{~min}$. The pellet was mixed with $1 \mathrm{X}$ assay buffer. JC-1 fluorescence was measured to assess the emission shift from green $(530 \mathrm{~nm})$ to red $(590 \mathrm{~nm})$ using the $488 \mathrm{~nm}$ excitation wavelength. Data were given as the relative ratio of green to red fluorescence intensities, indicating the level of depolarization of the mitochondrial membrane potential. The FACSCalibur flow cytometer (BD Biosciences) was used for analysis. Data were quantified and expressed as the percentage of mitochondrial membrane potential decline relative to control cells.

Western blot analysis. The collected cells were lysed and the protein concentrations quantitated using BCA assay (Pierce Biotechnology, Rockford, IL, USA). The total $20 \mu \mathrm{g}$ of protein was resolved by electrophoresis through SDS-PAGE gel. The gel was transferred to nitrocellulose filters, blocked with $5 \%$ of skim milk (BD Biosciences, Mansfield, MA, USA) and incubated with primary antibody for $24 \mathrm{~h}$ followed by horseradish-conjugated secondary antibodies. The emitted chemiluminescence signals were visualized by ECL detection kit (Millipore, Darmstadt, Germany).

Transfection with small hairpin RNA (shRNA). The HepG2 hepatocellular carcinoma cells were seeded at $5 \times 10^{5}$ cells/dish in $60-\mathrm{mm}$ dishes and incubated overnight. Cells were trans- 

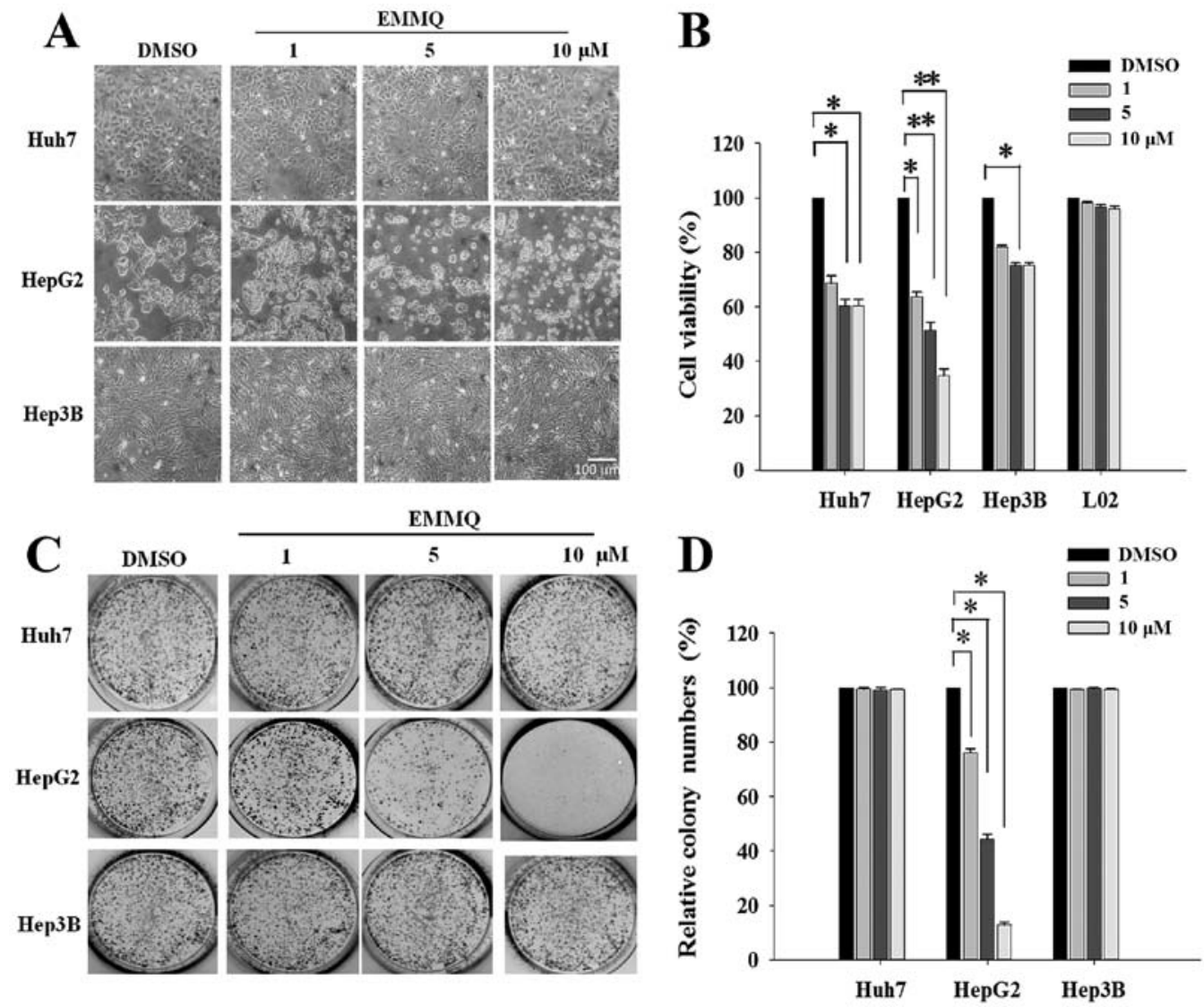

Figure 1. Effects of EMMQ on cell growth in HCC and human hepatic cells. (A) Cells were treated with $0,1,5$ and $10 \mu \mathrm{M}$ EMMQ for $48 \mathrm{~h}$ and their morphological changes observed under light microscope (magnification, x100). The apparent changes in HepG2 cells by the increasing EMMQ concentrations were not observed in Huh7 and Hep3B cells (scale, $100 \mu \mathrm{m}$ ). (B) EMMQ inhibits the growth of HepG2 cells. The cells were cultured in 96-well plate for $48 \mathrm{~h}$ and then treated with various concentrations of EMMQ as indicated. The relative cell viability were converted from the absorbance of drug-treated cells against that of DMSO vehicle control. Data are presented as the mean values \pm standard deviation (SD). ${ }^{*} \mathrm{P}<0.05$ and ${ }^{* * *} \mathrm{P}<0.01$ indicate a significant difference of three independent experiments. (C) EMMQ inhibits the growth of HepG2 colonies. Colony formation capacity was determined by plating 500 cells in 12 -well plates. Cells were treated with various concentrations of EMMQ or vehicle control for $48 \mathrm{~h}$. After continuous culture in drug-free complete media for ten days, the colonies were stained with $0.05 \%$ crystal violet as dissolved in PBS and recorded. (D) Statistical analysis. The number of colonies, defined as $>50$ cells per colony, was counted. The relative colonies were determined as the ratio of the numbers in samples of treatment against those of DMSO control. Triplicate wells were conducted for each condition. Data are presented as the mean values $\pm \mathrm{SD}$. ${ }^{*} \mathrm{P}<0.05$ and ${ }^{* * *} \mathrm{P}<0.01$ indicated significant differences.

fected with shRNA targeting of p53 with non-specific shRNA (NS) as control prior to treatment. After a period of $24-\mathrm{h}$ transfection, cells were treated with EMMQ for $48 \mathrm{~h}$. Cell lysates were collected for western blot analysis. Small hairpin RNA targeting RNA sequence of p53 (CACCAUCCACUA CAACUACAU) along with that of scrambled NS gene (CC GGACACUCGAGCACUUUUUG) were acquired from the National RNAi Platform (Academia Sinica, Taipei, Taiwan).

Isolation of mitochondria and cytosol fractions. Mitochondria and cytosol fractions were separated using the kit according to the manufacturer's instructions (BioVision, Milpitas, CA, USA). The total $5 \times 10^{5}$ cells were collected after centrifugation at $600 \mathrm{x} \mathrm{g}$ for $5 \mathrm{~min}$ at $4^{\circ} \mathrm{C}$. Cells were washed with $10 \mathrm{ml}$ of ice-cold PBS and centrifuged at $600 \mathrm{x}$ g for $5 \mathrm{~min}$ at $4^{\circ} \mathrm{C}$. The supernatant was removed. Cells were mixed with $1.0 \mathrm{ml}$ of $1 \mathrm{X}$ cytosol extraction buffer mixture containing DTT and protease inhibitors and incubated on ice for $10 \mathrm{~min}$. The homogenate was transferred to a $1.5 \mathrm{ml}$ microcentrifuge tube and centrifuged at $700 \mathrm{x} \mathrm{g}$ for $10 \mathrm{~min}$ in $4^{\circ} \mathrm{C}$. The supernatant was gathered and the pellet discarded. The collected supernatant was centrifuged at $10,000 \times \mathrm{g}$ for $30 \mathrm{~min}$ at $4^{\circ} \mathrm{C}$. The super- natant was stored at $-80^{\circ} \mathrm{C}$ (cytosol fraction) and the pellets were resuspended in $100 \mu 1$ of $1 \mathrm{X}$ mitochondrial extraction buffer mixture containing 1,4-dithiothreitol (Aldrich-Sigma) and protease inhibitors. The mitochondrial fraction mixture was stored at $-80^{\circ} \mathrm{C}$. Both lysed cytosol and mitochondrial fractions were used for western blot analysis.

Statistical analysis. Experiments were performed independently three times. The differences between the treated and the control cells were analyzed using the Student's t-test between the two groups, or one-way ANOVA was applied to compare more than two groups. The data were expressed as mean values $\pm \mathrm{SD}$ of three independent experiments and $\mathrm{P}<0.05$ considered statistically significant.

\section{Results}

EMMQ inhibits cell proliferation in human liver cancer cells. Morphological examination showed that HepG2 cells became round and blunt in shape with smaller sizes as EMMQ concentrations were increased after 48 -h treatment; while there was no effect observed in Huh7 and Hep3B cells (Fig. 1A). The 
A
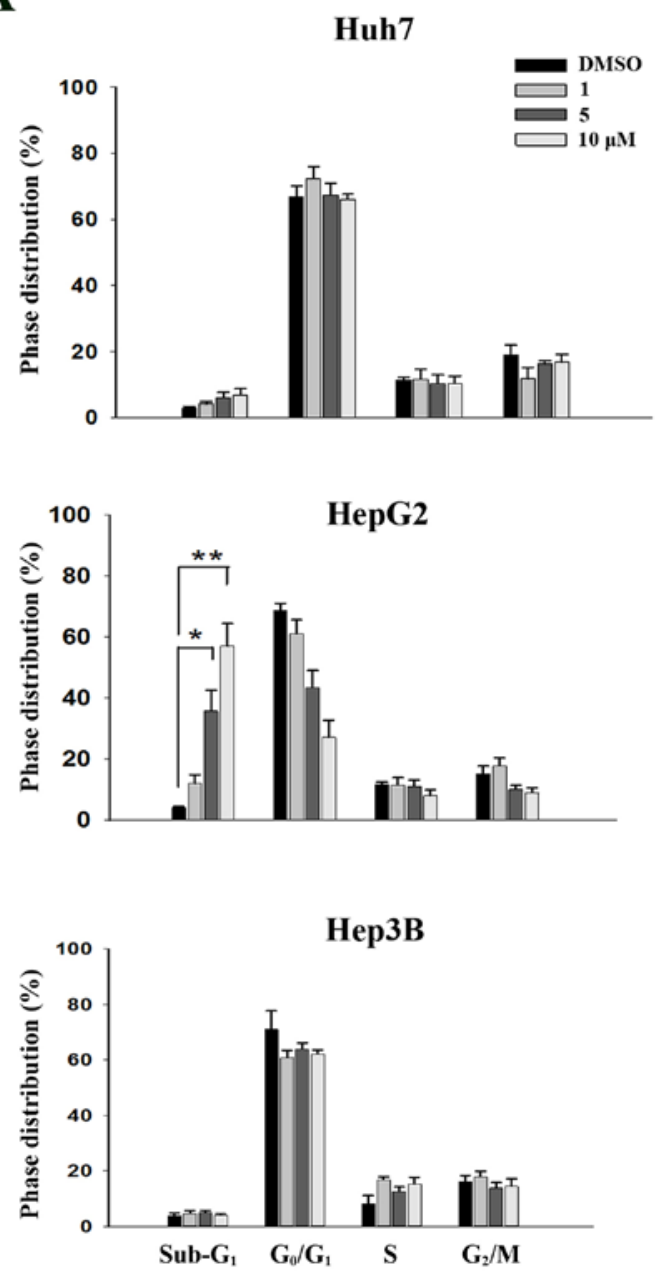

D

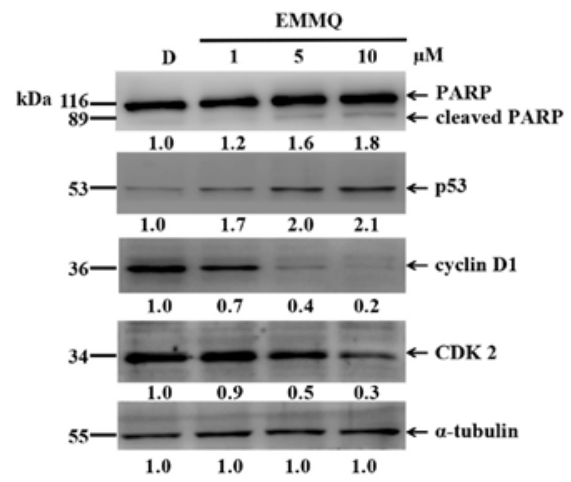

B
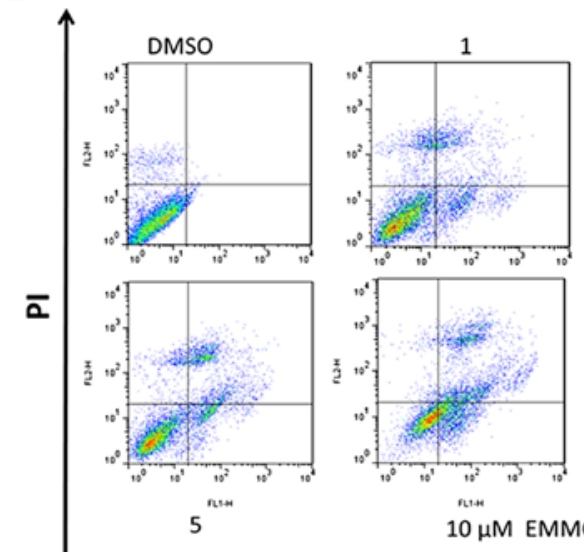

$10 \mu \mathrm{M}$ EMMQ

Annexin V-FITC

C

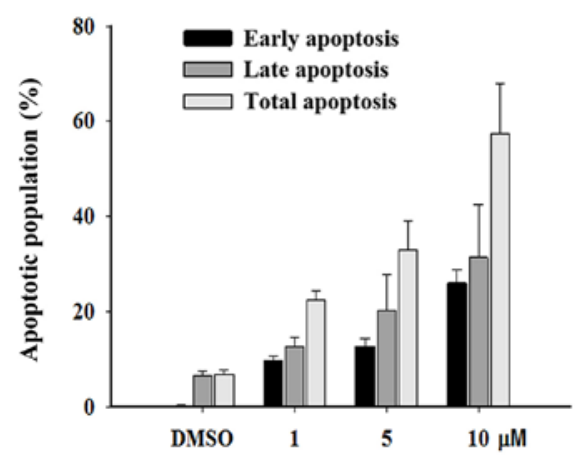

$\mathbf{E}$

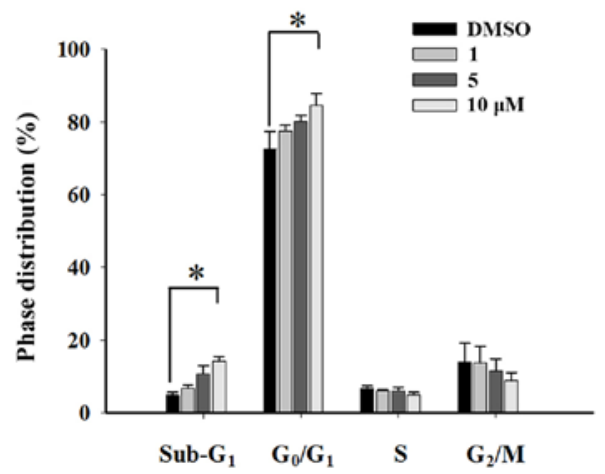

Figure 2. EMMQ treatment induced cell cycle distribution changes. (A) Huh7, HepG2 and Hep3B cells were treated with various concentrations of EMMQ, stained with PI and determined for cell cycle distribution by flow cytometry as described in Materials and methods. The sub- $\mathrm{G}_{1}$ phase cells were increased with escalating EMMQ concentrations in HepG2 cell after $48 \mathrm{~h}$. ${ }^{*} \mathrm{P}<0.05$ and ${ }^{* *} \mathrm{P}<0.01$. (B) Two-dimensional flow analysis in cells treated with various concentrations of EMMQ for $48 \mathrm{~h}$ and analyzed by flow cytometry after double staining cells with Annexin V-FITC/PI. (C) Quantitative analysis of apoptotic cell populations. Both the early (dark), late (grey) and total (light) apoptotic population distribution in cells treated with various concentrations of EMMQ or DMSO control, D, are expressed as mean values \pm SD from three independent experiments. (D) Protein lysates as collected from HepG2 cells after treating with various concentrations of EMMQ for $24 \mathrm{~h}$ were subjected to western blot analysis by incubating with antibodies against PARP, p53, cyclin D1, CDK2 and control $\alpha$-tubulin, followed by 1:3,000 dilution of horseradish peroxidase-conjugated secondary antibody and then developed by ECL detection system. The numbers underneath each band signify relative intensities at each concentration by comparing with that of vehicle control DMSO, D. (E) The induced $\mathrm{G}_{0} / \mathrm{G}_{1}$ cell accumulation in HepG2 cells after $24 \mathrm{~h}$ with various concentrations of EMMQ as analyzed by PI-stained flow cytometry. ${ }^{*} \mathrm{P}<0.05$.

EMMQ-reduced cell viability in HepG2 cells was dose-dependent with an $\mathrm{IC}_{50}$ of $5 \mu \mathrm{M}$ as shown in MTT assay (Fig. 1B). No apparent growth inhibition was observed in Huh7 and Hep3B cells or normal human hepatic cells L02 within the concentrations studied. In addition, the colony formation capacity was significantly suppressed in HepG2 cells with increasing EMMQ concentrations (Fig. 1C). The number of colonies was reduced to $<50 \%$ of the control as the drug concentration was raised to $5 \mu \mathrm{M}$ and there showed no apparent inhibitory effect in cells with mutated p53 (Fig. 1D). 

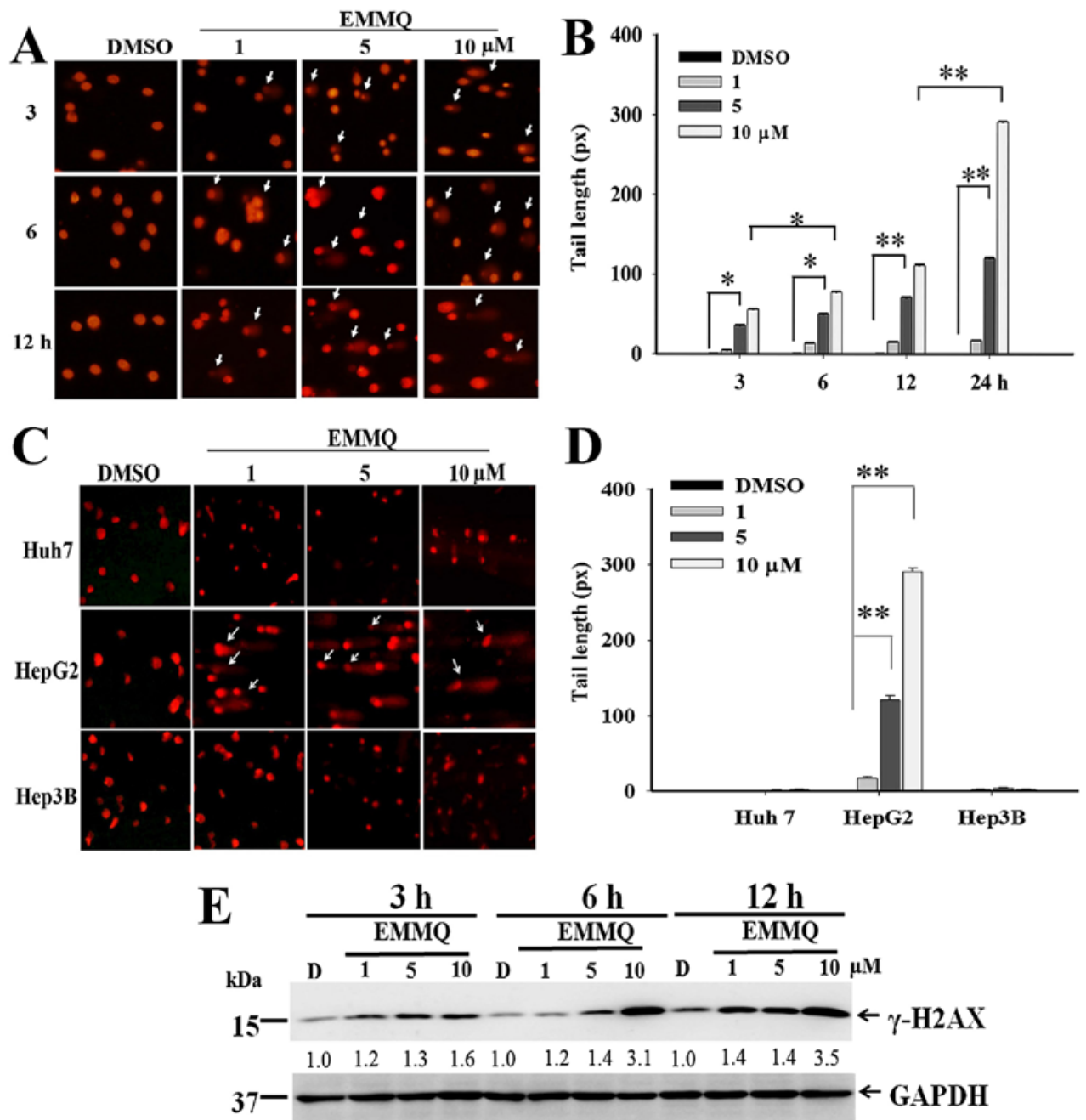

Figure 3. EMMQ induced DNA damage (A) HepG2 cells were treated with various concentrations of EMMQ for the time periods as indicated. The collected cells were evaluated for DNA damage by comet assay as described in Materials and methods. The apparent tail formation (pointed arrow) marked time- and dose-dependent DNA damage. (B) HepG2 cells as treated with EMMQ at various concentrations for 3, 6, 12 and 24 h, respectively, were analyzed for their DNA tail formations as observed under a fluorescence microscope. The results were quantified using CometScore ${ }^{\mathrm{TM}}$ software and scored for tail moments that equal the measured tail length multiplied with fraction of total DNA in the tail. The tail moments were expressed as mean values $\pm \mathrm{SD}$ and ${ }^{*} \mathrm{P}<0.05$ and ${ }^{* *} \mathrm{P}<0.01$ indicate a significant difference from three independent experiments. (C) All Huh7, HepG2 and Hep3B cells were treated with EMMQ at various concentrations for $24 \mathrm{~h}$. Cells were evaluated for DNA damage by comet assay. The increased DNA damage appeared as smeared tail (pointed arrow) in HepG2 cells. (D) All Huh7, HepG2 and Hep3B cells were treated with EMMQ at various concentrations for $24 \mathrm{~h}$. The results of comet assay were quantified using CometScore ${ }^{\mathrm{TM}}$ software and scored for tail moments that equal the measured tail length multiplied with fraction of total DNA in the tail. The tail moments were expressed as mean values \pm SD and ${ }^{*} \mathrm{P}<0.05$ and ${ }^{* *} \mathrm{P}<0.01$ indicate a significant difference from three independent experiments. (E) Protein lysates as collected from HepG2 cells after treating with various concentrations of EMMQ for 3,6 and $12 \mathrm{~h}$ were examined for western blot analysis with GAPDH (glyceraldehyde-3-phosphate dehydrogenase) as loading control. The blots were incubated with $\gamma$-H2AX antibody, followed by secondary antibody and visualized by ECL detection system. The numbers underneath represented relative intensities by comparing treatment of various concentrations with that of vehicle control DMSO, D, at each time-point.

EMMQ increases sub- $G_{1}$ population cells, $G_{1}$ arrest and apoptosis in HepG2 cells. To evaluate whether EMMQ disturbed cell cycle distribution, cells were treated with various concentrations of the drug for $48 \mathrm{~h}$ and analyzed by flow cytometry following PI staining. Compared with vehicle control, EMMQ increased sub- $\mathrm{G}_{1}$ populations in HepG 2 cells and the effects were dose-dependent, while both Huh7 and Hep3B cells were not changed (Fig. 2A). Furthermore, HepG2 cells exposed to various concentrations of EMMQ were analyzed by Annexin V and PI double staining-based assay flow cytometry (Fig. 2B). By treating with $10 \mu \mathrm{M}$ of EMMQ for $48 \mathrm{~h}$, cells of early and late apoptotic phase populations rose to 27 and $31 \%$, respectively (Fig. 2C). The results implied that the enhanced sub- $\mathrm{G}_{1}$ populations contributed to decreased cell viabilities in HepG2 cells.
To assure DNA was affected during cell cycle variation, western blot analysis of protein lysates in HepG2 cells treated with EMMQ for $24 \mathrm{~h}$ showed that p53 began activated and PARP was cleaved. The suppressed cyclin D1 and CDK2 expression (Fig. 2D) starting with $5 \mu \mathrm{M}$ of EMMQ progressively arrested cells (Fig. 2E) before the onset of apoptosis.

EMMQ induces HepG2 cell apoptosis because of DNA damage. The extent of DNA damage at various concentrations and different time-points were determined by comet assay. The nucleus-excluded tails with migration smear indicating DNA lesions emerged $3 \mathrm{~h}$ after EMMQ treatment (Fig. 3A). The dose-dependent development of the excluded tail length in HepG2 cells began $3 \mathrm{~h}$ after EMMQ treatment and rose temporally (Fig. 3B). There is no apparent tail length forma- 
A

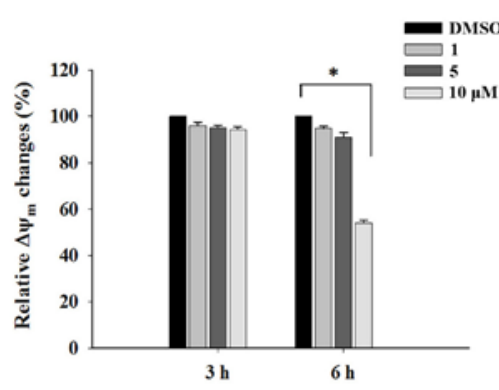

C

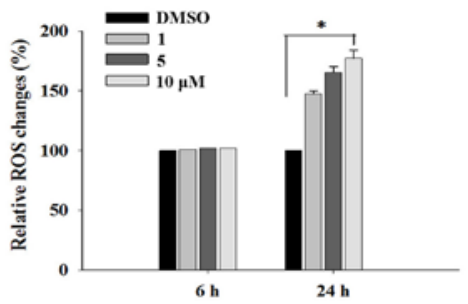

B

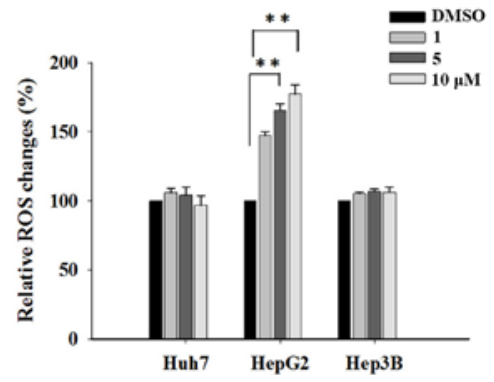

D

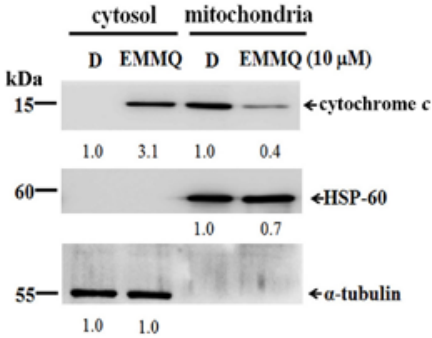

$\mathbf{E}$

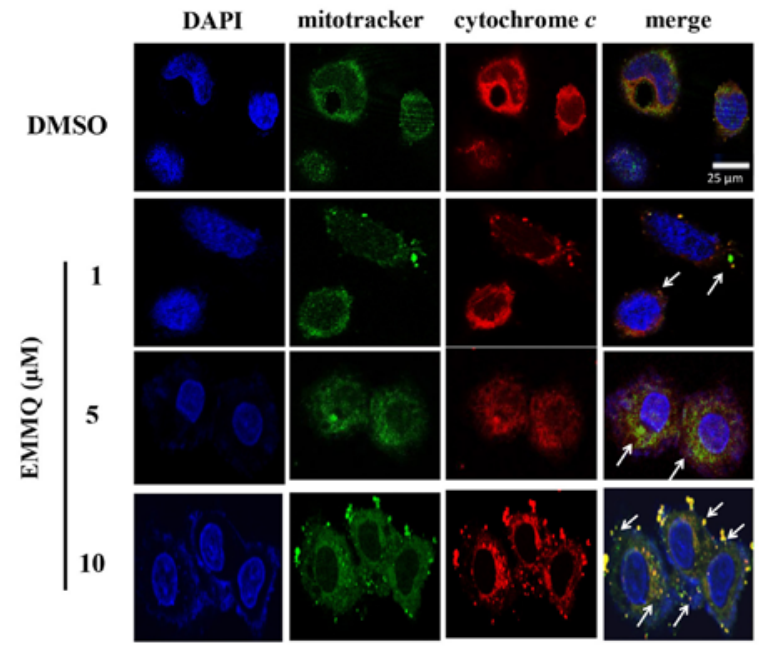

Figure 4. EMMQ reduces mitochondrial membrane potential $(\Delta \Psi \mathrm{m})$ and enhances cytochrome $c$ release in HepG2 cells. (A) $\Delta \Psi \mathrm{m}$ changes after EMMQ treatment. Cells treated with various concentrations of EMMQ in HepG2 cells for 3 and $6 \mathrm{~h}$ were evaluated for relative $\Delta \Psi \mathrm{m}$ changes. Data are presented as the mean values $\pm \mathrm{SD}$. $\mathrm{P}<0.05$ indicated a significant difference with vehicle control DMSO in HepG2 cells from three independent experiments. (B) Relative ROS changes. The Huh7, HepG2 and Hep3B cells were treated with various concentrations of EMMQ for $24 \mathrm{~h}$. For each cell line, the detected ROS levels were compared with that of cells treated with DMSO that served as $100 \%$ control. ${ }^{* *} \mathrm{P}<0.01$ indicated a significant difference against the vehicle control cells from three independent experiments. (C) Temporal ROS changes in HepG2 cells. Cells treated with different concentrations of EMMQ in HepG2 cells after 6 and $24 \mathrm{~h}$ were evaluated for relative ROS changes. Data are presented as the mean values $\pm \mathrm{SD}$. ${ }^{*} \mathrm{P}<0.05$ indicates a significant difference against vehicle control in HepG2 cells from three independent experiments. (D) Western blot analysis. The lysates of the respective mitochondrial and cytosolic fractions from HepG2 cells after 24-h treatment of EMMQ were collected as described in Materials and methods. The protein was subjected to western blot analysis. The blots were incubated with antibodies against cytosol marker, $\alpha$-tubulin, mitochondria markers, HSP-60, and cytochrome $c$, respectively, followed by incubation with a 1:3,000 dilution of horseradish peroxidase-conjugated secondary antibody and then developed by ECL detection system. The numbers underneath signify relative intensities compared with the results of DMSO, D, treatment. (E) The released mitochondrial cytochrome $c$ in HepG2 cells treated with 1,5 or $10 \mu \mathrm{M}$ of EMMQ or vehicle control DMSO for $24 \mathrm{~h}$ were fixed and incubated with antibody against cytochrome $c$ followed by incubating with secondary antibody conjugated with TRITC (red). The slides were counterstained with mitotracker (green) and DAPI (blue) before being analyzed by confocal microscopy. The pointed arrows signify co-localization of red color cytochrome $c$ and green color mitochondria, while blue indicates the nucleus (scale, $25 \mu \mathrm{m}$ ).

tion in Huh7 and Hep3B cells within the concentrations studied after 24-h treatment (Fig. 3C and D).

Western blot analysis showed that EMMQ activated double-strand DNA break marker $\gamma$-H2AX after 3-h treatment. The increased drug concentrations accentuated time-course increment of DNA damage signals (Fig. 3E). The results suggested that human liver cancer cells with wild-type p53 were susceptible to DNA damage by EMMQ.
EMMQ induces HepG2 cells apoptosis through mitochondrial membrane permeabilization $(\Delta \Psi \mathrm{m})$ loss and ROS production. The mitochondria-related apoptotic pathway can be linked to membrane potential disruption that signaled dysfunction of the organelle. After 6-h treatment, EMMQ initiated loss of $\Delta \Psi \mathrm{m}$ by more than $50 \%$ in HepG2 cells compared with vehicle control (Fig. 4A). As cells undergo stress, ROS contributed to cell cycle arrest or final apoptosis. 


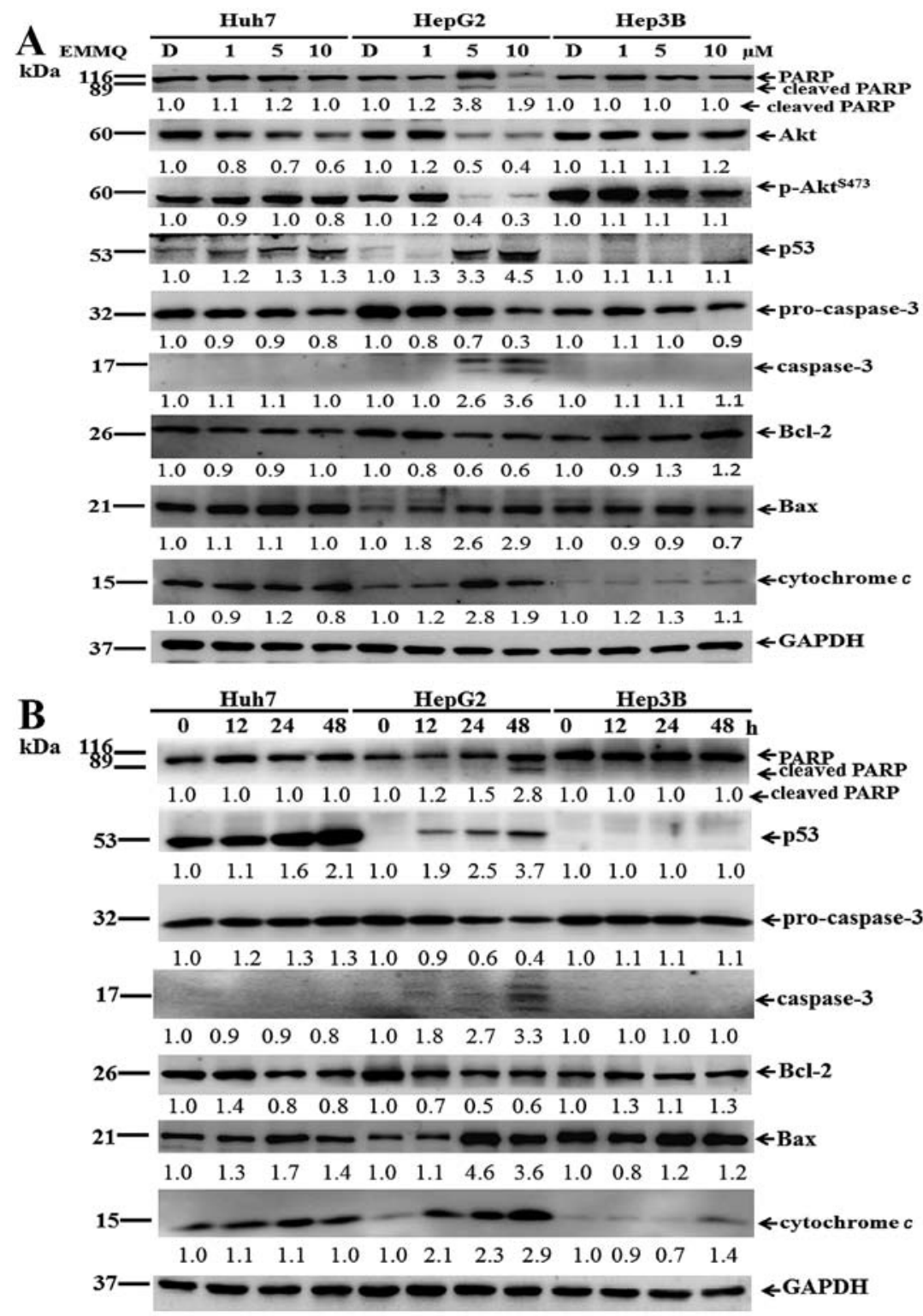

Figure 5. Western blot analysis of EMMQ-treated cell lysates. (A) The protein lysates from Huh7, HepG2 and Hep3B cells as treated with 1, 5 and $10 \mu \mathrm{M}$ of EMMQ for $48 \mathrm{~h}$ were collected followed by western blot analysis as described in Materials and methods. The blots were incubated with various primary and secondary antibodies as specified with GAPDH (glyceraldehyde-3-phosphate dehydrogenase) as loading control. The numbers underneath signify intensities relative to that of vehicle control DMSO, D, in each cell line. (B) Western blot proteins from lysates in cells treated with $5 \mu \mathrm{M}$ of EMMQ for various time-points $(0,12,24$ and $48 \mathrm{~h})$ were examined by western blot analysis. The numbers underneath signify intensities relative to those at $0 \mathrm{~h}$ of each cell line.

Flow cytometry in cells stained with fluorescent dye DCF-DA is a good marker to measure membrane potential variations. Compared to DMSO treatment, the increased fluorescence intensities as measured by flow cytometry suggested that intracellular ROS was developed in HepG2 cells by EMMQ, but not in Hep3B and Huh7 cells (Fig. 4B), and the intensities arose to more than $50 \%$ after $24-\mathrm{h}$ treatment relative to control (Fig. 4C).

EMMQ induces mitochondrial cytochrome c release in HepG2 cells. The impaired mitochondrial functions were further established by cytochrome $c$ release in HepG2 cells after 24-h treatment with increasing drug concentrations. Western blot analysis of the protein lysates in the collected cells showed that the increased intensity of cytochrome $c$ in cytosol by EMMQ relative to vehicle control were at the expense of that in mitochondria (Fig. 4D). More experiments with confocal microscopy showed that the puncta composing of coalesced cytochrome $c$ signal and mitochondria marker were more apparent in HepG2 cells with increasing EMMQ concentrations (Fig. 4E). The results altogether proved that EMMQ induced release of cytochrome $c$ into cytosol following DNA damage in HepG2 cells.

Apoptosis by activating the intrinsic pathway. To prove that DNA damage contributed to apoptosis, protein lysates of the cells were subjected to western blot analysis. The increased concentrations of EMMQ activated p53 after $48 \mathrm{~h}$. In addition, levels of $\mathrm{Akt}, \mathrm{p}-\mathrm{Akt}^{\mathrm{S}}{ }^{473}, \mathrm{Bcl}-2$ and procaspase- 3 were reduced; while those of Bax, cytochrome $c$, cleaved caspase- 3 and fragmented poly(ADP ribose) polymerase (PARP) became apparent in HepG2 cells (Fig. 5A). On the other hand, when 
A

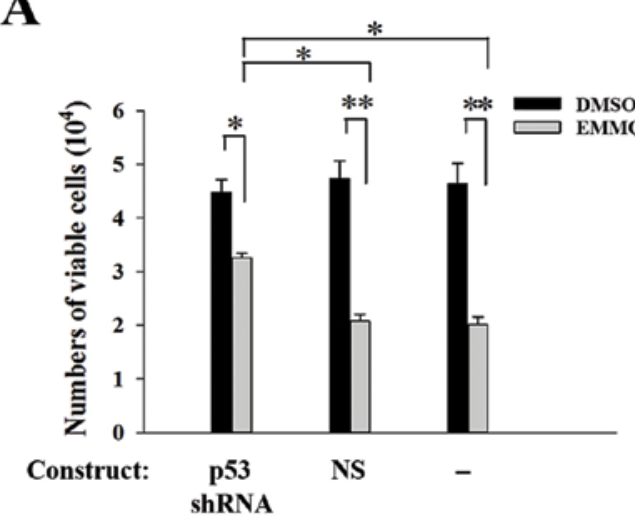

C
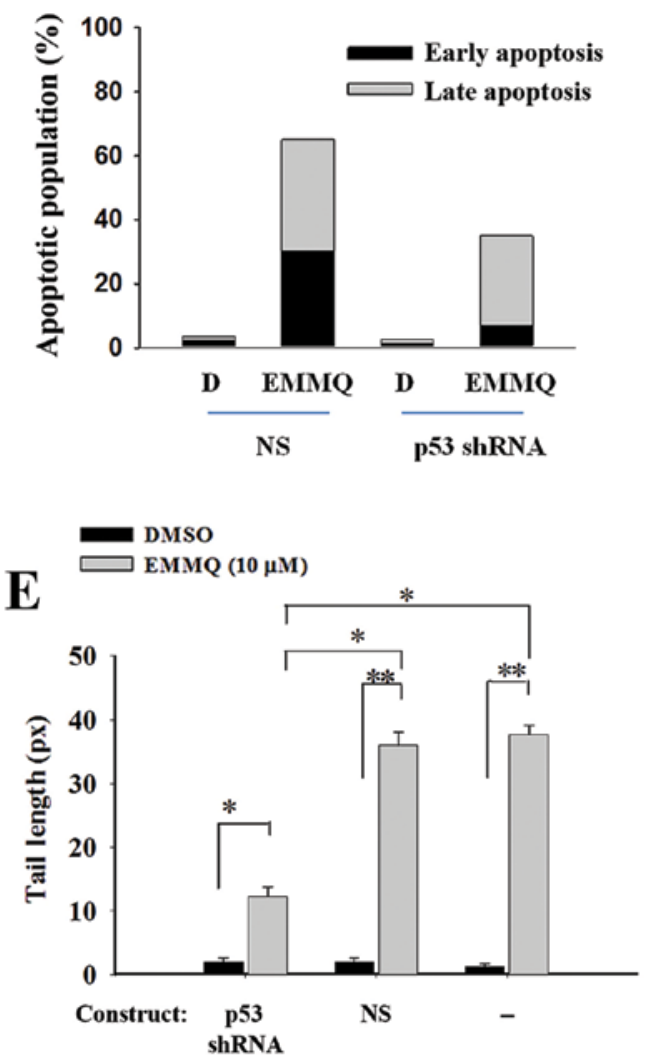

B

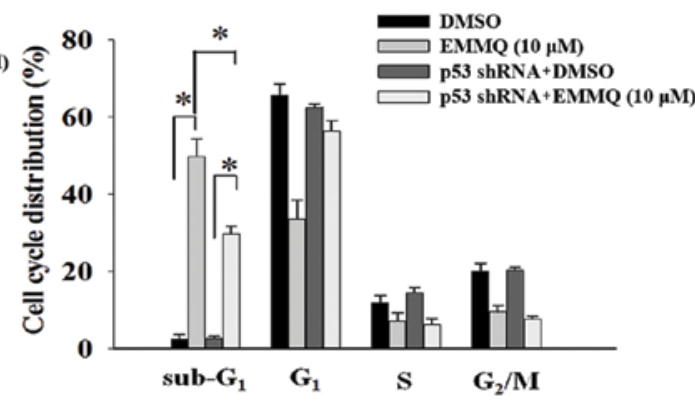

D
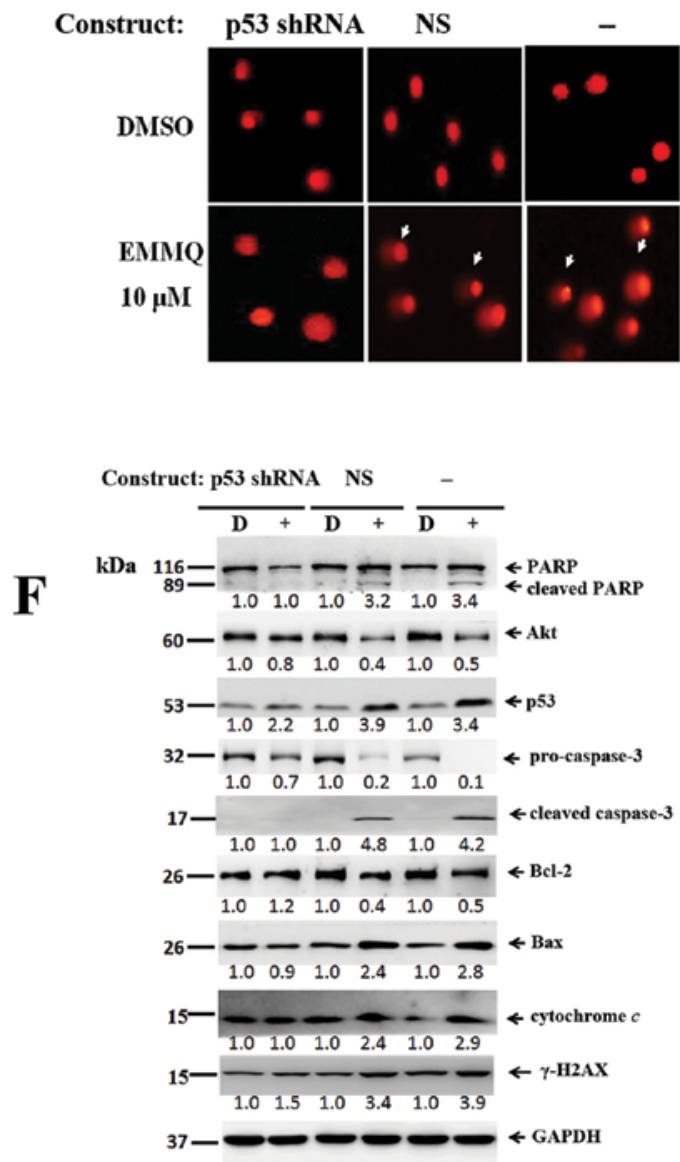

Figure 6. Effects of p53 shRNA on EMMQ-induced cell death in HepG2 cells. (A) The viable cells were counted by trypan-blue exclusion assay. The numbers at each condition including p53 shRNA and NS control were compared between $48 \mathrm{~h}$ drug treatment and DMSO control. Symbol (-) indicates no transfection. ${ }^{*} \mathrm{P}<0.05$ and ${ }^{* *} \mathrm{P}<0.01$ indicated a significant difference between groups. Symbol (-) marked no transfection. (B) Cells transfected with p53 shRNA or NS control were treated with EMMQ or control DMSO for $48 \mathrm{~h}$ and stained with PI to determining cell cycle distribution by flow cytometry. "P<0.05 indicated the significance of difference. (C) Cells transfected with p53 shRNA or NS control were treated with EMMQ or control DMSO, D, for $48 \mathrm{~h}$ and stained with Annexin V/PI for determining distributions of early and late apoptosis as total apoptotic population by flow cytometry. The result showed the representative of three individual experiments. (D) HepG2 cells were transfected with either p53 shRNA or NS control for $24 \mathrm{~h}$ and then treated with $10 \mu \mathrm{M}$ EMMQ for $48 \mathrm{~h}$. The extruded DNA tail (pointed arrow) as stained were measured as described in Materials and methods. (E) The extruded tail length by comet assay were quantified using CometScore ${ }^{\mathrm{TM}}$ software. ${ }^{*} \mathrm{P}<0.05$ and ${ }^{* *} \mathrm{P}<0.01$ indicated the significance of difference against DMSO control at each condition, in which (-) signified no transfection. (F) Western blot analysis of proteins from HepG2 cells transfected with p53 shRNA and NS control with GAPDH (glyceraldehyde-3-phosphate dehydrogenase) as loading control. In each condition, the numbers of relative intensities between EMMQ treatment (+) and DMSO control, D, were shown underneath, and symbol (-) marked no transfection.

incubated with $5 \mu \mathrm{M}$ of EMMQ, time-dependent p53 activation, procaspase-3 dissipation, caspase-3 development plus PARP cleavage in HepG2 cells indicated temporal progression of apoptotic cell death. Furthermore, the increased Bax and cytochrome $c$ plus the reduced Bcl-2 suggested that the developed apoptosis is related to mitochondria dysfunction; whereas both Hep3B and Huh7 cells were unaffected (Fig. 5B). The results implied that EMMQ-induced apoptosis was attributed 


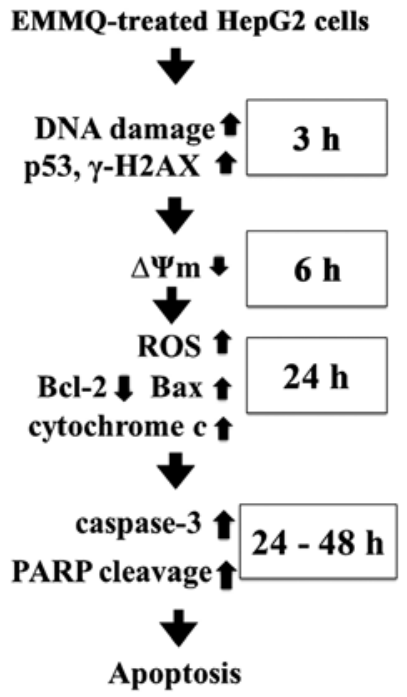

Figure 7. Working model of EMMQ-mediated apoptosis. EMMQ-induced DNA damage and cell cycle arrest and then activated intrinsic pathwaymediated apoptosis in HepG2 cells. First, EMMQ-increased DNA lesions stimulated expression of p53 and $\gamma-\mathrm{H} 2 \mathrm{AX}$ and decreased mitochondrial membrane potential $(\Delta \Psi \mathrm{m})$ and elevated ROS. Second, activated tumor suppressor $\mathrm{p} 53$ attenuated $\mathrm{Bcl}-2$, increased Bax and cytochrome $c$ release that activated caspase- 3 fragmentation and cleavage of PARP. The events are critical in leading apoptotic cell death of HepG2 cells.

to p53 activation following DNA damage and the subsequent mitochondria impairment.

Downregulated p53 abolishes EMMQ-induced cell death. To assure that p53 was crucial in modulating cell death, experiments by transfecting shRNA targeting exon 7 of p53 to cells before drug treatment were performed along with those of non-specific shRNA (NS) control. The resultant cell viabilities were unaffected by EMMQ in HepG2 cells, indicating that p53 shRNA eliminated drug sensitivity relative to cells introduced with NS control (Fig. 6A). The suppressed sub-G T $_{1}$ cells (Fig. 6B) and the restrained early and late phase populations as measured by PI and Annexin V double staining flow cytometry (Fig. 6C) suggested drug sensitivity was reduced as a result. The diminished DNA lesions in HepG2 cells transfected with p53 shRNA indicated that knocking down p53 impeded EMMQ-mediated DNA damage (Fig. 6D and E). Western blot analysis showed that cells transfected with p53 shRNA not only blocked p53 activation, but attenuated cleavage of PARP and procaspase-3, inhibited caspase- 3 fragmentation, reduced expression of Bax, deterred mitochondrial cytochrome $c$ release and $\gamma$-H2AX enhancement, while pro-survival genes Bcl-2 and Akt were unchanged (Fig. 6F). Taken altogether, the results proved that p53 shRNA stalled the apoptotic cell death in HCC cells through mitigating DNA damage and restoring mitochondrial integrity and the status of p53 determines the effectiveness of EMMQ.

\section{Discussion}

$\mathrm{HCC}$ is among the most common malignances and the second most frequent cause of cancer death (1). The highly aggressive tumor responds poorly to common therapies (9). Several early trials were evaluated by targeting therapy. Among them, the approved drug sorafenib for advanced HCC suppressed tumor growth by inhibiting kinases in the MAPK pathway, inducing autophagy, suppressing tumor cell proliferation and promoting apoptosis (10). Another approved drug sunitinib for treatment is a multi-targeted receptor tyrosine kinase inhibitor. The drug blocks the tyrosine kinase activities of KIT, PDGFR, VEGFR2 and other tyrosine kinases during tumor development (11). Most traditional chemotherapy exhibited low response rate in curing HCC (12). Thus, more new effective and well-tolerated therapy strategies are needed. This study showed that EMMQ suppressed the growth of HCC cells, while normal hepatic cells remained unaffected. The cell death as activated began with DNA damage. The reduced growth can be attributed to apoptotic cell death (Fig. 2A-C).

The cell death as activated by EMMQ began with DNA damage. Response to the damaged DNA included accumulated cellular processes, such as recognition, damage signal amplification, cell cycle control, DNA repair and apoptosis. Many anticancer drugs induced cell apoptosis by activating p53 when encountering DNA damage (13). As DNA integrity was severed, $\gamma-\mathrm{H} 2 \mathrm{AX}$ facilitates phosphorylation of histone by interacting with p53. Thus, the double-strained DNA damage marker $\gamma-\mathrm{H} 2 \mathrm{AX}$ is crucial in the repair process (14) and final apoptosis (15). The increased DNA lesion by EMMQ began as early as $3 \mathrm{~h}$ in HepG 2 cells. The increased drug concentrations augmented temporal development of detrimental effects (Fig. 3A-D) and activated p53 (Fig. 5B). As an index of DNA damage, $\gamma-\mathrm{H} 2 \mathrm{AX}$ motivation that emerged at $3 \mathrm{~h}$ (Fig. 3E) acts together with p53 in response to DNA damage (16) and arrests cells at $\mathrm{G}_{1}$ phase by inhibiting synthesis of cyclindependent kinases (17). In response to DNA damage, p53 acts as a sequence-specific transcription factor that orchestrates the appropriate cellular response by inducing cell cycle arrest and apoptosis $(18,19)$. The study showed that, as EMMQ damaged DNA in HepG2 cells, p53 intensities and PARP cleavage were augmented by the increased EMMQ concentrations, while both cyclin D1 and CDK2 levels were decreased. The data were consistent with the result that EMMQ arrested cell growth by holding the cell cycle at the $G_{0} / G_{1}$ checkpoint when encountering DNA damage after $24 \mathrm{~h}$ (Fig. 2E).

The results further suggested that the accumulated DNA lesion attenuated $\Delta \Psi \mathrm{m}$ and produced ROS. The observation asserted that damaged DNA in HepG2 cells further injured mitochondria integrities. Cytochrome $c$ as appeared in cytosol (Fig. 4D) and released from mitochondria (Fig. 4E) implied progressive impairment of mitochondrial functions. By forming complexes with members of Bcl-2 family, p53 interrupted mitochondrial outer membrane entirety (20). The previous report (8) showed that EMMQ directly induced dysfunction of mitochondrial by releasing cytochrome $c$ into cytosol before apoptotic cell death in NSCLC cells. In the case of HepG2 cells, the released cytosolic cytochrome $c$ from mitochondria occurred following DNA damage after $24 \mathrm{~h}$-treatment. The present study demonstrated that EMMQ-induced apoptosis in liver cancer began with DNA damage prior to $\Delta \Psi \mathrm{m}$ attenuation, ROS production and release of mitochondrial cytochrome $c$.

Similar small quinoline molecules were reported effective in restraining the growth of cancer cells. A previous study showed that the $\mathrm{IC}_{50}$ value of 6-methoxy-8-[(2-furanylmethyl) amino]-4-methyl-5-(3-trifluoromethylphenyloxy)quinoline is $16 \pm 3 \mathrm{nM}$ in inhibiting breast cancer cells (21). Another similar 
compound, PQ1, 6-methoxy-8-[(3-aminopropyl)amino]4-methyl-5-(3-trifluoromethylphenyloxy)quinoline induced apoptosis in T47D breast cancer cells (22). PQ15, 6-methoxy-4methyl-8-[(4-quinolinylmethyl)amino]-5-(3-trifluoromethyl phenyloxy)-quinoline affected viability of T47D breast cancer cells (23). Treatment with combined indole-3-carbinol and genistein induced apoptosis in human colon cancer HT-29 cells (24). Indolylquinoline derivatives are mostly used to treat leishmaniasis $(25,26)$. The present study provided a different aspect of indolylquinoline EMMQ for human HCC treatment, in which the damaging nucleus directly activated p53 and produced ROS that mediated final apoptotic cell death. As a DNA-binding transcriptional regulator, p53 contributes to cell cycle arrest and apoptosis (27) by activating downstream elements to stall growth or promote cell death during genotoxic stress (28-30). More reports showed that ROS induces apoptosis by inducing mitogen-activated protein kinases (MAPKs) (31) and the increased ROS is associated with p53 activation $(32,33)$. The attenuated $\Delta \Psi \mathrm{m}$, diminished outer membrane regulator Bcl-2 and release of downstream modulator mitochondrial cytochrome $c$ were attributed to outer mitochondrial membrane permeabilization $(34,35)$. There were reports that $\mathrm{Akt}, \mathrm{Bcl}-2$ and Bax modulation were associated with activated p53 (36-38). The present study showed that EMMQ induced apoptosis in liver cancer cells through p53 activation, Akt downregulation, Bcl-2 reduction and caspase-3 fragmentation. Knocking down p53 suppressed the drug effects by mitigating DNA damage and preserving mitochondria integrity. Whether EMMQ is effective to treat other types of cancer or those that metastasize to distant sites remains to be seen.

In conclusion, the indolylquinoline derivative EMMQ injured DNA first in liver cancer cells that differed from previous findings in NSCLC cells. The damaged DNA suppressed $\Delta \Psi \mathrm{m}$ before apoptosis in human HCC cells carrying p53. The injured DNA activated p53 and increased expression of $\gamma-\mathrm{H} 2 \mathrm{AX}$, while the decreased cyclin D1 and CDK2 arrested cells at $G_{0} / G_{1}$ phase. The subsequent attenuated pro-survival signal Akt, decreased Bcl-2/Bax ratio, released mitochondrial cytochrome $c$, cleavage of both procaspase-3 and PARP accelerated apoptotic cell death in HepG2 cells (Fig. 7). Attenuation of p53 inhibited drug sensitivity. The study asserted the role of EMMQ as a potential candidate to treat a subset of liver cancer.

\section{Acknowledgements}

The present study was supported by grants from the Ministry of Science and Technology, Executive Yuan, ROC (MOST 103-2311-B-003-001) and the National Taiwan Normal University (102T3040B2, 103T3040D2 and 104T3040C2). We would like to thank the College of Life Science and Instrumentation Center, National Taiwan University for their technical assistance of the confocal laser microscopy.

\section{References}

1. Jemal A, Bray F, Center MM, Ferlay J, Ward E and Forman D: Global cancer statistics. CA Cancer J Clin 61: 69-90, 2011.

2. Ferlay J, Soerjomataram I, Dikshit R, Eser S, Mathers C, Rebelo M, Parkin DM, Forman D and Bray F: Cancer incidence and mortality worldwide: Sources, methods and major patterns in GLOBOCAN 2012. Int J Cancer 136: E359-E386, 2015.
3. Kumar M, Zhao X and Wang XW: Molecular carcinogenesis of hepatocellular carcinoma and intrahepatic cholangiocarcinoma: One step closer to personalized medicine? Cell Biosci 1: 5, 2011.

4. Brown KS: Chemotherapy and other systemic therapies for hepatocellular carcinoma and liver metastases. Semin Intervent Radiol 23: 99-108, 2006.

5. Cao H, Phan H and Yang LX: Improved chemotherapy for hepatocellular carcinoma. Anticancer Res 32: 1379-1386, 2012.

6. Terazawa T, Kondo S, Hosoi H, Morizane C, Shimizu S, Mitsunaga S, Ikeda M, Ueno H and Okusaka T: Transarterial infusion chemotherapy with cisplatin plus S-1 for hepatocellular carcinoma treatment: A phase I trial. BMC Cancer 14: 301, 2014.

7. Jiang L, Zhang Q, Ren H, Ma S, Lu C, Liu B, Liu J, Liang J, Li M and Zhu R: Dihydromyricetin enhances the chemo-sensitivity of nedaplatin via regulation of the $\mathrm{p} 53 / \mathrm{Bcl}-2$ pathway in hepatocellular carcinoma cells. PLoS One 10: e0124994, 2015.

8. Liu CY, Wu PT, Wang JP, Fan PW, Hsieh CH, Su CL, Chiu CC, Yao $\mathrm{CF}$ and Fang $\mathrm{K}$ : An indolylquinoline derivative promotes apoptosis in human lung cancer cells by impairing mitochondrial functions. Apoptosis 20: 1471-1482, 2015.

9. Lee WY, Cheung CC, Liu KW, Fung KP, Wong J, Lai PB and Yeung JH: Cytotoxic effects of tanshinones from Salvia miltiorrhiza on doxorubicin-resistant human liver cancer cells. J Nat Prod 73: 854-859, 2010.

10. Gauthier A and Ho M: Role of sorafenib in the treatment of advanced hepatocellular carcinoma: An update. Hepatol Res 43: 147-154, 2013.

11. Hartmann JT and Kanz L: Sunitinib and periodic hair depigmentation due to temporary c-KIT inhibition. Arch Dermatol 144: $1525-1526,2008$

12. Sukowati CH, Rosso N, Crocè LS and Tiribelli C: Hepatic cancer stem cells and drug resistance: Relevance in targeted therapies for hepatocellular carcinoma. World J Hepatol 2: 114-126, 2010.

13. Banin S, Moyal L, Shieh S, Taya Y, Anderson CW, Chessa L, Smorodinsky NI, Prives C, Reiss Y, Shiloh Y, et al: Enhanced phosphorylation of p53 by ATM in response to DNA damage. Science 281: 1674-1677, 1998.

14. Hamer G, Roepers-Gajadien HL, van Duyn-Goedhart A, Gademan IS, Kal HB, van Buul PP and de Rooij DG: DNA double-strand breaks and gamma-H2AX signaling in the testis. Biol Reprod 68: 628-634, 2003.

15. Yuan J and Chen J: MRE11-RAD50-NBS1 complex dictates DNA repair independent of H2AX. J Biol Chem 285: 1097-1104, 2010.

16. Di Leonardo A, Linke SP, Clarkin K and Wahl GM: DNA damage triggers a prolonged p53-dependent G1 arrest and long-term induction of Cip1 in normal human fibroblasts. Genes Dev 8: 2540-2551, 1994.

17. Agarwal ML, Agarwal A, Taylor WR and Stark GR: p53 controls both the G2/M and the G1 cell cycle checkpoints and mediates reversible growth arrest in human fibroblasts. Proc Natl Acad Sci USA 92: 8493-8497, 1995.

18. Innocente SA, Abrahamson JL, Cogswell JP and Lee JM: p53 regulates a G2 checkpoint through cyclin B1. Proc Natl Acad Sci USA 96: 2147-2152, 1999.

19. Lakin ND and Jackson SP: Regulation of p53 in response to DNA damage. Oncogene 18: 7644-7655, 1999.

20. Assunção Guimarães C and Linden R: Programmed cell deaths. Apoptosis and alternative death styles. Eur J Biochem 271: 1638-1650, 2004.

21. Shi A, Nguyen TA, Battina SK, Rana S, Takemoto DJ, Chiang PK and Hua DH: Synthesis and anti-breast cancer activities of substituted quinolines. Bioorg Med Chem Lett 18: 3364-3368, 2008.

22. Ding Y and Nguyen TA: PQ1, a quinoline derivative, induces apoptosis in T47D breast cancer cells through activation of caspase-8 and caspase-9. Apoptosis 18: 1071-1082, 2013.

23. Bernzweig J, Heiniger B, Prasain K, Lu J, Hua DH and Nguyen TA: Anti-breast cancer agents, quinolines, targeting gap junction. Med Chem 7: 448-453, 2011.

24. Nakamura Y, Yogosawa S, Izutani Y, Watanabe H, Otsuji E and Sakai T: A combination of indol-3-carbinol and genistein synergistically induces apoptosis in human colon cancer HT-29 cells by inhibiting Akt phosphorylation and progression of autophagy. Mol Cancer 8: 100, 2009.

25. Chakrabarti G, Basu A, Manna PP, Mahato SB, Mandal NB and Bandyopadhyay S: Indolylquinoline derivatives are cytotoxic to Leishmania donovani promastigotes and amastigotes in vitro and are effective in treating murine visceral leishmaniasis. J Antimicrob Chemother 43: 359-366, 1999. 
26. Pal C, Raha M, Basu A, Roy KC, Gupta A, Ghosh M, Sahu NP, Banerjee S, Mandal NB and Bandyopadhyay S: Combination therapy with indolylquinoline derivative and sodium antimony gluconate cures established visceral leishmaniasis in hamsters. Antimicrob Agents Chemother 46: 259-261, 2002.

27. Brambilla E and Negoescu A: Analysis of Bax and Bcl-2 expression in p53-immunopositive breast cancers. Clin Cancer Res 3: 2181-2183, 1997.

28. Vaseva AV and Moll UM: The mitochondrial p53 pathway. Biochimica et Biophysica Acta 1787: 414-420, 2009.

29. Baker SJ, Fearon ER, Nigro JM, Hamilton SR, Preisinger AC, Jessup JM, vanTuinen P, Ledbetter DH, Barker DF, Nakamura Y, et al: Chromosome 17 deletions and p53 gene mutations in colorectal carcinomas. Science 244: 217-221, 1989.

30. Linke SP, Clarkin KC, Di Leonardo A, Tsou A and Wahl GM: A reversible, $\mathrm{p} 53$-dependent $\mathrm{G}_{0} / \mathrm{G}_{1}$ cell cycle arrest induced by ribonucleotide depletion in the absence of detectable DNA damage. Genes Dev 10: 934-947, 1996.

31. Saha S, Bhattacharjee P, Mukherjee S, Mazumdar M, Chakraborty S, Khurana A, Nayak D, Manchanda R, Chakrabarty R, Das T, et al: Contribution of the ROS-p53 feedback loop in thuja-induced apoptosis of mammary epithelial carcinoma cells. Oncol Rep 31: 1589-1598, 2014
32. Macip S, Igarashi M, Berggren P, Yu J, Lee SW and Aaronson SA: Influence of induced reactive oxygen species in $\mathrm{p} 53$-mediated cell fate decisions. Mol Cell Biol 23: 8576-8585, 2003.

33. Raha $\mathrm{S}$ and Robinson $\mathrm{BH}$ : Mitochondria, oxygen free radicals, disease and ageing. Trends Biochem Sci 25: 502-508, 2000.

34. Holley AK and St Clair DK: Watching the watcher: Regulation of 553 by mitochondria. Future Oncol 5: 117-130, 2009.

35. Mihara M, Erster S, Zaika A, Petrenko O, Chittenden T, Pancoska P and Moll UM: p53 has a direct apoptogenic role at the mitochondria. Mol Cell 11: 577-590, 2003.

36. Ji H, Ding Z, Hawke D, Xing D, Jiang BH, Mills GB and Lu Z: AKT-dependent phosphorylation of Niban regulates nucleophosmin- and MDM2-mediated p53 stability and cell apoptosis. EMBO Rep 13: 554-560, 2012.

37. Qian J, Zou Y, Rahman JS, Lu B and Massion PP: Synergy between phosphatidylinositol 3-kinase/Akt pathway and Bcl-xL in the control of apoptosis in adenocarcinoma cells of the lung. Mol Cancer Ther 8: 101-109, 2009.

38. Malki A and El Ashry S: In vitro and in vivo efficacy of a novel quinuclidinone derivative against breast cancer. Anticancer Res 34: 1367-1376, 2014. 